Ecology, 99(8), 2018, pp. 1897-1899

(C) 2018 by the Ecological Society of America

\section{Griffon Vultures scavenging at night: trophic niche expansion to reduce intraspecific competition?}

Vultures feed exclusively on carrion and so are the only obligate scavengers among extant vertebrates (Ruxton and Houston 2004). Because the occurrence of carrion is unpredictable, vultures soar over large areas during daylight searching for carrion with their keen eyesight (Ruxton and Houston 2004). Although some data exist on vultures departing or arriving at roosts at dusk or dawn, respectively (Nathan et al. 2012), foraging outside daylight hours has only been reported in American Black Vultures (Coragyps atratus; Charette et al. 2011). We document here a new foraging behavior of Griffon Vultures Gyps fulvus, scavenging at night (Fig. 1), which has not been described in Old World vultures and adds to the repertory of unexpected behaviors reported for the species.

At least 14 different Griffon Vultures were recorded feeding on two naturally dead cows Bos taurus $(\sim 400-500 \mathrm{~kg}$ each) during five nights in summer 2014 in alpine pastures of northwestern Spain (Fig. 1; Appendix S1). Vultures were recorded scavenging a mean of $\sim 3 \mathrm{~h}$ per night (range: $33 \mathrm{~min}-6 \mathrm{~h}$; i.e., between sunset, 22:08, and sunrise, 06:43, local time UTC+2) by motion-triggered remote cameras (Fig. 1a, c). Griffon Vultures scavenged at night only at these two carcasses out of 93 carcasses of wild and domestic ungulates monitored in the study area during 2011-2014 (i.e., 2\%; Appendix S1; Mateo-Tomás et al. 2017). Vultures fed on the remaining carcasses exclusively during the day (i.e., mean 12:50 hours; Rayleigh and Rao tests, $P<0.001$; $N=91$ carcasses). The two carcasses here reported appeared in the afternoon (mean \pm SE: 17:26 hours \pm 1 h $51 \mathrm{~min}$ ); these times were not significantly different from those of other ungulate carcasses in the area (13:50 hours $\pm 40 \mathrm{~min}$, Kolmogorov-Smirnov test for fitting a lognormal distribution, $P=0.062 ; N=20$ carcasses). Vultures arrived at both carcass types at approximately the same time after the animals died (i.e., $25.9 \pm 0.6$ h vs. $40.7 \pm 10.1 \mathrm{~h} ; P=0.184$ ).

Because Vultures arrive at carcasses first and in higher numbers than other scavengers, they outcompete other scavengers (Ruxton and Houston 2004) through exploitation competition and thus consume most of the carrion. Some individual Griffon Vultures exclude others at carcasses through aggressive displays or attacks, thus also displaying high levels of intraspecific competition (Bosè and Sarrazin
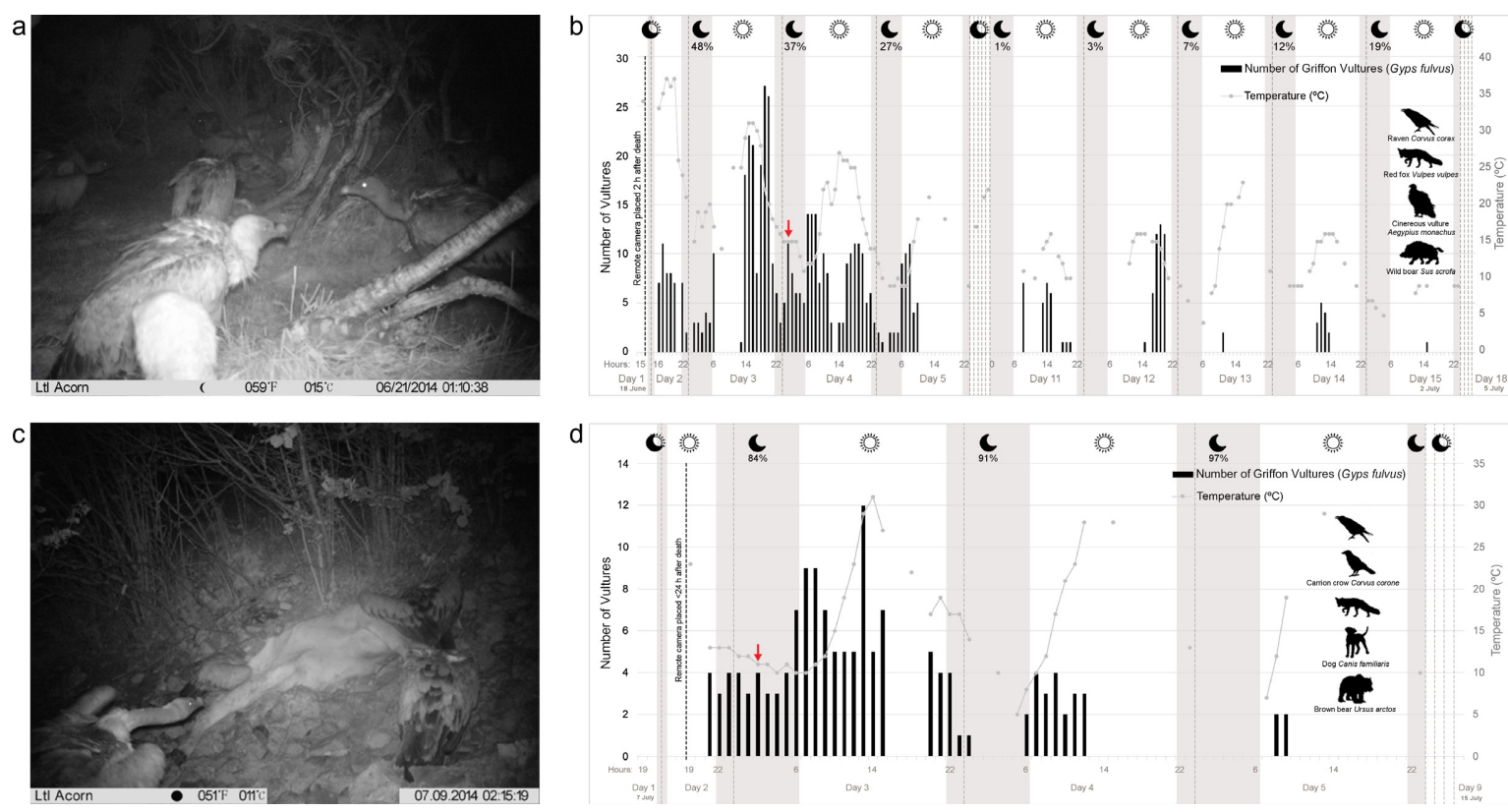

Fig. 1. Griffon Vultures were recorded scavenging at night at two cow carcasses (a, c) in Somiedo Natural Park $\left(291 \mathrm{~km}^{2}\right.$ in northwestern Spain). The number of Griffon Vultures scavenging per hour (local time: UTC+2) is shown in panels b and d (bars, left $y$-axis). Vertical red arrows indicate when the photographs shown were taken (see also time stamps on a and c). Besides sunny, warm, and rainless weather favoring Vulture foraging during daylight, higher nocturnal temperatures $\left({ }^{\circ} \mathrm{C}\right.$; gray dotted line, right $y$-axis) during the nights when Vultures scavenged than when they did not (i.e., mean $\pm \mathrm{SE}, 13.9^{\circ} \pm 0.6^{\circ} \mathrm{C}$ vs. $8.1^{\circ} \pm 0.6^{\circ} \mathrm{C} ; P<0.001$ ) and moonlight $>27 \%$ may facilitate Vulture nocturnal activity by minimizing heath loss and allowing vision of potential threats. Black silhouettes indicate other species recorded scavenging in order of appearance at each carcass. 
2007). Since species' niche width results from balancing the expansive forces of intraspecific competition against the constraining forces of interspecific competition (Bolnick et al. 2010), the Griffon Vulture is liable to undergo trophic niche variations, especially when food is scarce, as scarcity boosts conspecific aggregation and thus intraspecific competition. Indeed, Griffon Vultures are able to track the distribution of carrion (Olea and Mateo-Tomás 2009) and show extraordinary individual foraging behaviors such as unusual long-distance movements, feeding at rubbish dumps, or attacking livestock (Margalida et al. 2010).

In accordance with the optimal foraging theory (Schoener 1971) and the niche variation hypothesis (Van Valen 1965), we hypothesize that the observed Griffon Vultures scavenged at night to maximize energy net gain through reducing intraspecific competition and therefore aggression during daytime, therefore promoting an expansion of the population temporal trophic niche. In fact, the minimum number of Vultures simultaneously scavenging per hour at the two monitored carcasses was significantly lower during the night (i.e., mean $\pm \mathrm{SE}=4 \pm 1$ ) than during the day (i.e., $8 \pm 1, P<0.001$; Wilcoxon test, $W=1,867$; Fig. 1 b, d), consistent with our hypothesis of a nocturnal reduction of intraspecific competition. High levels of intraspecific competition apparently reduces the profitability of accessing carrion during daytime to the point that scavenging at night becomes relatively profitable, thereby driving individual niche expansion under reduced interspecific competition (Bolnick 2001, Bolnick et al. 2010).

The population densities (a proxy for intraspecific competition) increase with individual niche variation in several species (Araújo et al. 2011). In our study area, the density of Griffon Vultures increases at least by $120 \%$ during summer when livestock are present (Olea and Mateo-Tomás 2009). The existence of a large summer roost, used by at least 98 different Griffon Vultures (Olea and Mateo-Tomás 2009), <30 km away from the monitored carcasses exceeds by far the mean size of breeding colonies in the area (i.e., mean $\pm \mathrm{SE}=$ $4.9 \pm 0.4$ breeding pairs; Mateo-Tomás and Olea 2011). This may increase the foraging group size and intraspecific competition through interference (Bosè and Sarrazin 2007).

Intraspecific competition increases also when preferred resources, e.g., large carcasses in our case, are scarce (Araújo et al. 2011). For patchy resources such as carrion, an individual will abandon a patch when the net gain diminishes to the average of the environment (Schoener 1971). For Vultures feeding at night, carrion availability in the study area should be low at the time of our observations. According to the ideal free distribution theory (Fretwell and Lucas 1969), Vultures should then switch to other carcasses to escape intraspecific competition at individual carcasses. However, food availability in the study area during our observations could be insufficient for supporting the increasing summer Vulture population. Livestock presence in the study area rises from $\mathrm{mid} /$ late June (e.g., $\sim 2,000$ sheep and $\sim 14,000$ cows within $10 \mathrm{~km}$ around the above referred summer roost in 2007; Olea and Mateo-Tomás 2009) until July and August (e.g., $\sim 16,000$ sheep and $\sim 15,000$ cows), i.e., slightly after the observations of Vultures scavenging at night (Fig. 1).
Furthermore, sheep, which have higher and more constant mortality rates than cows (i.e., $2.0 \%$ vs. $0.8 \%$, respectively), arrive in late June-early July, and the mortality of cows is greatest mainly in autumn (Olea and Mateo-Tomás 2009).

The fact that nocturnal foraging occurred on the first three days after carcass appearance (Fig. 1b, d) supports the hypothesis of competition for food, agreeing with higher foraging activity observed in hungry Vultures (Spiegel et al. 2013). Because carcasses are an unpredictable resource, Vultures consume as much as possible once they found a carcass. They are adapted to cope with fasting periods of up to two weeks, not needing to eat every day (e.g., every three days on average in Israel; Spiegel et al. 2013).

For net energy gain, the costs of Griffon Vultures feeding at night (e.g., risk of predation or injury, especially by nocturnal mammalian scavengers; Spiegel et al. 2013) should be lower than the benefits. Our observations suggest that these costs were low at the monitored carcasses. Despite wolves (Canis lupus) and bears (Ursus arctos) being facultative scavengers in the study area (Mateo-Tomás et al. 2017), only red foxes (Vulpes vulpes) co-occurred at night with Vultures at the monitored carcasses. Large-bodied Vultures easily excluded this medium-sized species through direct size effect (Ruxton and Houston 2004), therefore incurring low or no costs from interference behavior (P. Mateo-Tomás and $\mathrm{P}$. Olea, personal observation). Vulture niche expansion to scavenge at night could affect the dynamics of the scavenging community through altering temporal niche segregation between diurnal (mostly birds) and nocturnal (mammals) scavengers. Since Vultures are extraordinarily good competitors at carcasses, they could decrease carrion availability for nocturnal scavengers (i.e., top predators and generalists; Mateo-Tomás et al. 2017).

Regarding alternative hypotheses explaining the observed nocturnal behavior, although bad weather (e.g., rainy) might prevent diurnal foraging by Vultures (Charette et al. 2011), the two monitored carcasses were consumed during sunny, warm, and rainless days (Fig. 1b, d). Although some vultures have developed a keen sense of smell (Houston 2001) that might aid in night foraging, the only vulture species registered hitherto foraging at night (i.e., American Black and Griffon Vultures) do not use the sense of smell but use keen eyesight to find food. Olfactory acuity does not seem therefore to play any role in the observed nocturnal behavior. Because we have not marked individuals, we do not know if the observed behavior corresponded to specific individuals adapted to forage at night or was more widespread among Vultures. In this regard, the potential role of personality differences associated with this (and others) unusual foraging behavior should be explored (Wolf and Weissing 2012).

Intraspecific competition can be a potent evolutionary force (Bolnick 2001) and among-individual variability is also of particular concern in evolutionary studies (Araújo et al. 2011), so further attention should be paid to assessing the ecological and evolutionary implications of the high behavioral plasticity shown by Griffon Vultures, especially under the current scenario of increasing human-mediated carrion (Oro et al. 2013). The extent to which human-induced changes in carrion availability (e.g., sanitary policies 
concerning carcass abandonment in the field, transhumance decrease; Olea and Mateo-Tomás 2009, Margalida et al. 2010) could affect the trophic niche of Griffon Vultures and other scavengers deserves further attention.

\section{ACKNOWLeDGMENTS}

We thank J. Tomás, J. S. Fuster, environmental authorities from Principado de Asturias, and two anonymous reviewers as well as funding from the REMEDINAL-3 (S-2013/MAE2719) project.

\section{Literature Cited}

Araújo, M. S., D. I. Bolnick, and C. A. Layman. 2011. The ecological causes of individual specialization. Ecology Letters 14:948958.

Bolnick, D. I. 2001. Intraspecific competition favours niche width expansion in Drosophila melanogaster. Nature 410:463-466.

Bolnick, D. I., T. Ingram, W. E. Stutz, L. K. Snowberg, O. L. Lau, and J. S. Paull. 2010. Ecological release from interspecific competition leads to decoupled changes in population and individual niche width. Proceedings of the Royal Society B 277:1789-1797.

Bosè, M., and F. Sarrazin. 2007. Competitive behavior and feeding rate in a reintroduced population of griffon vultures Gyps fulvus. Ibis 149:490-501.

Charette, M., F. Pelletier, and S. Calmé. 2011. Observation of nocturnal feeding in black vultures (Coragyps atratus). Journal of Raptor Research 45:279-280.

Fretwell, S. D., and H. L. J. Lucas. 1969. On territorial behavior and other factors influencing habitat distribution in birds. Acta Biotheoretica 19:16-36.

Houston, D. 2001. Vultures \& condors. Colin Baxter Photography, Grantown-on-Spey, UK.

Margalida, A., J. A. Donázar, M. Carrete, and J. A. SánchezZapata. 2010. Sanitary versus environmental policies: fitting together two pieces of the puzzle of European vulture conservation. Journal of Applied Ecology 47:931-935.

Mateo-Tomás, P., and P. P. Olea. 2011. The importance of social information in breeding site selection increases with population size in the Eurasian Griffon Vulture Gyps fulvus. Ibis 153:832-845.

Mateo-Tomás, P., P. P. Olea, M. Moleón, N. Selva, and J. A Sánchez-Zapata. 2017. Both common and rare species support ecosystem services in scavenger communities. Global Ecology and Biogeography 26:1459-1470.
Nathan, R., O. Spiegel, S. Fortmann-Roe, R. Harel, M. Wikelski, and W. M. Getz. 2012. Using triaxial acceleration data to identify behavioral modes of free-ranging animals: general concepts and tools illustrated for griffon vultures. Journal Experimental Biology 215:986-996.

Olea, P. P., and P. Mateo-Tomás. 2009. The role of traditional farming practices in ecosystem conservation: the case of transhumance and vultures. Biological Conservation 142:1844-1853.

Oro, D., M. Genovart, G. Tavecchia, M. S. Fowler, and A. MartínezAbraín. 2013. Ecological and evolutionary implications of food subsidies from humans. Ecology Letters 16:1501-1514.

Ruxton, G. D., and D. C. Houston. 2004. Obligate vertebrate scavengers must be large soaring fliers. Journal of Theoretical Biology 228:431-436.

Schoener, T. W. 1971. Theory of feeding strategies. Annual Review of Ecology and Systematics 2:369-404.

Spiegel, O., R. Harel, W. M. Getz, and R. Nathan. 2013. Mixed strategies of griffon vultures' (Gyps fulvus) response to food deprivation lead to a hump-shaped movement pattern. Movement Ecology 1:5.

Van Valen, L. 1965. Morphological variation and width of ecological niche. American Naturalist 99:377-390.

Wolf, M., and F. J. Weissing. 2012. Animal personalities: consequences for ecology and evolution. Trends in Ecology and Evolution 27:452-461.

\section{Patricia Mateo-Tomás ${ }^{1,2,4}$ and Pedro P. Olea ${ }^{3}$}

Manuscript received 20 January 2018; revised 4 April 2018; accepted 11 April 2018. Corresponding Editor: John Pastor.

${ }^{1}$ Department of Life Sciences, Centre for Functional Ecology, University of Coimbra, Calçada Martim de Freitas, 3000-456 Coimbra, Portugal.

${ }^{2}$ Institute for Game and Wildlife Research (IREC), Ronda de Toledo 12, Ciudad Real, Spain

${ }^{3}$ Terrestrial Ecology Group (TEG), Departamento de Ecología, Universidad Autónoma de Madrid, 28049 Madrid, Spain.

${ }^{4}$ E-mail: rktespejos@gmail.com

Additional supporting information may be found in the online version of this article at http://onlinelibrary.wiley.com/doi/10.1002/ ecy.2366/suppinfo 